\title{
ESTUDIANTES INDÍGENAS Y AFRODESCENDIENTES EN INSTITUCIONES CONVENCIONALES Y UNIVERSIDADES COMUNITARIAS
}

José Saballos Velásquez ${ }^{[1]}$

\section{Introducción}

Desde hace 23 años, los pueblos indígenas y afrodescendientes de la Costa Caribe de Nicaragua escriben un nuevo capítulo en su historia por el reconocimiento efectivo de los derechos particulares y su transformación hacia la dignidad en la libre autodeterminación y mejores condiciones de vida. Esta historia inició el 12 de Febrero de 1894 cuando la Reserva de la Mosquitia fue tomada por fuerzas armadas de Nicaragua. La Reserva de la Mosquitia -extendida desde San Juan del Norte en la latitud $11^{\circ}$ hasta Cabo Honduras en la latitud $16^{\circ}$ y 40 millas tierra adentro desde la costa-, era un territorio de autogobierno bajo la protección de Gran Bretaña, con quien la población miskita sostenía una alianza político, militar y comercial desde mediados de 1600. La incorporación de la Mosquitia fue precedida por dos actos importantes. El primero fue la firma del Tratado Clayton - Bulwer en 1850 entre los gobiernos de Gran Bretaña y Estados Unidos, donde prácticamente Gran Bretaña cedía a Estados Unidos su control geopolítico del Caribe. El segundo acto fue la firma del Tratado Zeledón, Wyke o Tratado de Managua en 1860 entre los gobiernos de Nicaragua y Gran Bretaña donde Gran Bretaña cedía la Reserva de la Mosquitia a Nicaragua, aunque con la condición de respetar su autonomía política- administrativa (Zapata, 2007). Se debe mencionar que en su alianza con Gran Bretaña, los pueblos indígenas (principalmente el miskito) pudieron evitar la Conquista y Colonización Española en el hoy Caribe nicaragüense, y con ello, evitaron su exterminio y/o mestizaje a como sucedió en el Pacífico, Centro y Norte del país.

De sus tres regiones naturales, la Costa Caribe es la región más extensa del país. Esta comprende $67,906.90 \mathrm{~km}^{2}$ de territorio y 716,236 habitantes, que corresponde al 56.43 por ciento del territorio nacional y al 13.93 por ciento de la población total de Nicaragua (INEC, 2006). La Costa Caribe está política y administrativamente dividida en el departamento de Río San Juan, la Región Autónoma Atlántico Norte (RAAN) y la Región Autónoma Atlántico Sur (RAAS). Ambas Regiones Autónomas representan el 50.16 por ciento del territorio nacional y el 12.07 por ciento de la población total del país. La RAAN y la RAAS se ubican en la posición seis y siete en población total, en relación a los quince departamentos y dos regiones en que se divide el país. Las

[1] Máster en Planificación y Gestión de Proyectos, Director de la Oficina de Cooperación Internacional de la URACCAN. jose. saballos@uraccan.edu.ni 
Regiones Autónomas son el territorio con la mayor riqueza en recursos naturales con alto valor económico (marinos, bosques, ríos y lagunas, humedales, minerales y petróleo) y la mayor diversidad sociocultural y lingüística del país. En ella habitan tres pueblos indígenas (miskito, sumo- mayangna y el rama), los pueblos afrodescendientes (kriol y garífuna) y dos tipos de población mestiza (costeña una y la recién migrada del Pacífico Centro, la otra).

A través de este documento se pretende una reflexión interna en la Universidad de las Regiones Autónomas de la Costa Caribe Nicaragüense (URACCAN), sobre los alcances de la atención a los pueblos indígenas y afrodescendientes en sus principales programas de formación, tanto en la función de docencia como de la extensión social y comunitaria. Este comprende tres secciones principales. En la primera sección, se aborda la cuestión indígena y afrodescendiente en Nicaragua desde el devenir de la Autonomía Regional, el principal marco jurídico de referencia del país de reconocimiento de derechos indígenas y afrodescendientes. La segunda sección establece el reto que los pueblos indígenas y afrodescendientes en relación al derecho en materia educativa en el país. La tercera sección aborda la atención a pueblos indígenas y afrodescendientes desde la experiencia de la URACCAN. Esta atención se aborda en las tres etapas fundamentales de ingreso, mantenimiento y graduación.

\section{La cuestión indígena y afrodescendiente en Nicaragua}

\section{El reconocimiento de la multiculturalidad}

En 1987, se logra el reconocimiento de la naturaleza multicultural y plurilingüe de la sociedad nicaragüense. En sus reformas promulgadas el 30 de Abril de 1987, la Constitución Política reconoce la existencia de los pueblos indígenas como sujetos de derechos, la multiculturalidad y el reconocimiento oficial de las lenguas de los pueblos indígenas y afrodescendientes (Título I de Principios Fundamentales, capítulo único, artículos 5, 8 y 11). En su Título IV de derechos, deberes y garantías del pueblo nicaragüense, capítulo VI de derechos de las comunidades de la Costa Atlántica, la Constitución incorpora el reconocimiento de los derechos de las comunidades de la Costa Atlántica a la identidad cultural, a las propias formas de organización social, a la administración de los asuntos locales conforme las tradiciones, la propiedad comunal y el aprovechamiento de los recursos en ellas (aguas y bosques), lengua, arte y cultura, y a la no discriminación por razones de lengua, cultura y origen (artículos 89, 90 y 91). En su Título IX sobre división político administrativa, se introduce las Regiones Autónomas (capítulo 1 de los municipios, artículo 175), las elecciones de autoridades regionales y el régimen de autonomía para esta parte del país (capítulo II de las comunidades de la Costa Atlántica, artículo 180 y 181). Estos reconocimientos constitucionales se incorporaron y ampliaron en diferentes leyes promulgadas posteriormente. 
El reconocimiento constitucional de la multiculturalidad tiene su principal instrumento jurídico en la Ley número 28 o "Estatuto de Autonomía de las Regiones de las Regiones de la Costa Atlántica de Nicaragua", que fue promulgada el 30 de octubre de 1987. En general, la Ley de autonomía, y su reglamento (promulgado el 2 de Octubre de 2003), se reconoce los derechos particulares políticos, sociales, económicos, culturales y ambientales de la población indígena y afrodescendientes, principalmente, de la Costa Caribe. En el ámbito político- administrativo, la Ley de Autonomía establece: la Región Autónoma Atlántico Norte (RAAN) y la Región Autónoma Atlántico Sur (RAAS) y dos órganos principales de administración dentro de las Regiones Autónomas, el Consejo Regional Autónomo y la Coordinación Regional. El primero, el órgano legislativo de la autonomía y el segundo es el ejecutivo. Otras derivaciones de leyes directas importantes son la Ley número 162: "Ley de Uso Oficial de las Lenguas de las Comunidades de la Costa Atlántica de Nicaragua" (promulgada el 15 de julio de 1996) y la Ley número 445 o "Ley del Régimen de Propiedad Comunal de los pueblos indígenas y Comunidades Étnicas de las Regiones Autónomas de la Costa Atlántica de Nicaragua y de los Ríos Bocay, Coco, Indio y Maíz". Los preceptos constitucionales autonómicos se han trasladado a leyes generales, como la Ley 423 o "Ley General de Salud" promulgada el 17 de Mayo de 2002, la Ley número 260 o "Ley Orgánica del Poder Judicial de la República de Nicaragua" y la Ley 582 o "Ley General de Educación" promulgada el 3 de Agosto de 2006. Este conjunto de preceptos legales constituye la legislación más avanzada de América Latina en materia de reconocimiento de derechos de pueblos indígenas y afrodescendientes.

El régimen de Autonomía, y su marco legal conexo, representan conquistas de los propios pueblos indígenas y afrodescendientes de la Costa Caribe de Nicaragua. La Ley de Autonomía se logra como parte de un proceso de pacificación que dejo atrás un cruento conflicto bélico acontecido en el período 1980- 1987 en la Costa Caribe. Los pueblos indígenas y afrodescendientes se movilizaron político- militarmente para reivindicar derechos históricos territoriales y de autogobierno, entre los principales, negados por las visiones y políticas etnocentristas, asimilacionistas, autoritarias y centralizadoras del Gobierno Sandinista. La Cruzada Nacional de Alfabetización en castellano, la explotación de los recursos naturales en tierras comunales por parte de Estado, la creación del Instituto Nicaragüense de la Costa Atlántica (INNICA) como ente desarrollista bajo una absoluta dirección mestiza del Pacífico, al igual que prácticamente todos los cargos en la Costa Caribe, fueron parte de estas políticas públicas (Frühling, González, \& Buvollen, 2007). Estos grandes errores del régimen sandinista, conjugados con la amenaza de la instauración del comunismo representada en el sandinismo, la severa crisis económica del momento y el apoyo del Gobierno de los Estados Unidos fueron factores decisivos que motivaron la insurgencia militar de la población multiétnica del Caribe nicaragüense. 


\section{El devenir de la Autonomía Regional}

La aprobación del Estatuto de Autonomía creó mucho entusiasmo y esperanzas en la población indígena y afrodescendiente de un mejor futuro. La Autonomía Regional inicia una nueva etapa en la relación entre el Estado nicaragüense, la población del Pacífico, Centro y Norte para los pueblos indígenas y afrodescendientes de la Costa Caribe. Desde la incorporación de la población del Caribe a Nicaragua en 1894, la población caribeña indígena principalmente había sufrido de exclusión, marginación, discriminación, racismo y el empobrecimiento. La Autonomía desde su concepto de autogobierno, crea la posibilidad de promover un ejercicio efectivo de derechos históricos colectivos, construir una ciudadanía multicultural y bienestar desde las prioridades locales y cosmovisión indígena y afrodescendiente. Estas posibilidades serían limitadas por las inconsistencias dentro del mismo Estatuto de Autonomía y las condiciones habilitadoras existentes en esta región.

Los principales vacíos e incongruencias existentes dentro del Estatuto de Autonomía al inicio de su aplicación eran varios. Los principales vacíos en el ámbito político- administrativo son la ausencia de especificidades sobre (i) las relaciones a desarrollarse entre los Consejos Regionales Autónomos y Gobiernos Regionales con las instituciones del Estado y sus delegaciones en la Costa Caribe, incluyendo el rol de las autoridades regionales dentro de las iniciativas impulsadas por estas, (ii) las relaciones entre Consejos y Gobiernos Regionales Autónomos con las Alcaldías Municipales y las estructuras tradicionales de gobierno de las comunidades, y (iii) las relaciones entre Consejos Regionales Autónomos y los Gobiernos Regionales Autónomos (Frühling, P. et al., 2007). Otros vacíos fundamentales del Estatuto de Autonomía refieren a no dejar establecido el financiamiento a los órganos autonómicos de parte del Estado, tanto vía asignación presupuestaria como de las facultades de establecer tributos regionales, al peso de la representación de los pueblos indígenas y afrodescendientes dentro de los Consejos Regionales Autónomos y la participación de los partidos políticos nacionales vis a vis los partidos políticos regionales. Por otro lado, las principales incongruencias del Estatuto de Autonomía se refieren a que el reconocimiento político de las comunidades y de las tierras comunales no estableció mecanismos y procedimientos de reconocimiento jurídico (Frühling, P. et al., 2007).

Estos vacíos e incongruencias se combinaron con una serie de condiciones adversas para determinar el estado actual del Régimen de Autonomía y de las condiciones de vida de la población de las Regiones Autónomas de la Costa Caribe. En 1990, con el inicio de la implementación de la Ley de Autonomía, la población de la Costa Caribe estaba sumida en su mayor crisis económica y social. La guerra había afectado severamente las actividades, áreas e infraestructura productiva y comercial, destruido una buena parte de la infraestructura social (educativa y de salud), causando un importante debilitamiento de las redes familiares y sociales en muchas comunidades y la emigración 
de valiosos recursos humanos calificados al extranjero (principalmente a Estados Unidos y Costa Rica). Por otro lado, las medidas de ajustes estructural impulsadas por el Gobierno de Violeta Barrios de Chamorro estaban reduciendo drásticamente la población empleada a través de las medidas de despidos masivos de trabajadores (polarmente conocidos como compactación) y expropiando a través de la privatización de los pocos activos productivos rentables provistos por la cooperación internacional a la sociedad Caribeña. En lo político, con las elecciones de 1990, se instauraba la polarización en la clase política nacional alrededor de los dos principales partidos (FSLN y PLC, uno de izquierda y el otro de derecha). En buena parte, esta clase política no conocía el proceso trascurrido hasta la aprobación de la Ley de Autonomía. Por otro lado, la Costa Caribe sur aún estaba en un proceso de rehabilitación después de la devastación causada por el huracán Joan, en octubre de 1988. El reto de las primeras autoridades regionales de iniciar un proceso de mejora de las condiciones de vida de la población caribeña en este contexto de crisis también estaba limitado por su poca experiencia política, bajo nivel de escolaridad, poca capacidad técnica disponible en la región para construir capacidad técnica institucional autonómica y la desconfianza interétnica tras una larga historia de conflictos. El panorama no podía ser más complicado.

Acercándonos a 23 años desde la promulgación del Estatuto de Autonomía, los avances del Régimen Autonómico no han cumplido con las expectativas de la población de la región. Los logros tangibles son deficitarios con respecto a los entusiasmos y esperanzas que se tenían con su aprobación. La población de las Regiones Autónomas de la Costa Caribe está entre la más pobre del país. En la Región Autónoma Atlántico Norte (RAAN) y la Región Autónoma Atlántico Sur (RAAS) la pobreza extrema embarga al 70.9 por ciento y 63.1 por ciento de la población, respectivamente (INIDE., 2007). Las dos Regiones Autónomas ocupan los dos primeros lugares en el país en pobreza extrema. De los 20 municipios de la RAAN y RAAS, 18 de ellos están calificados de extrema pobreza severa. Sus índices de pobreza extrema oscilan entre 87.4 por ciento a 56 por ciento. Los dos restantes municipios están calificados como de pobreza extrema alta (Muelle de los Bueyes con un 51.2 por ciento de extrema pobreza entre su población) y media (Corn Island con 40.9\%). La exclusión social y la discriminación no han dejado cesado de afectarla, principalmente cuando se refiere a los pueblos indígenas y afrodescendientes. Las Necesidades Básicas Insatisfechas (NBI) de los pueblos indígenas de las Regiones Autónomas se estima en un 83 por ciento general y en un 94.4 por ciento, 93.3 por ciento y 72.6 por ciento particular para los pueblos indígenas sumo- mayangna, miskito y rama respectivamente (Delgadillo, 2007). Entre los pueblos afrodescendientes, los kriol presentan un 84.6 por ciento y los garífuna un 75.5 por ciento de NBI (ibíd.).

Existen muchas y variadas causas del lento avance en resultados positivos en bienestar de la Autonomías Regional. A lo interno de las Regiones Autónomas, la alta inmigración de otras regiones del país, la corrupción y el tráfico de drogas son 
factores fundamentales de distorsión de las posibilidades reales de avance. En el período 1995- 2005, la población de las Regiones Autónomas creció en un 33.48 por ciento, es decir, a un tasa de 3.35 por ciento al año (INEC, 2006). En el período este fue el mayor incremento registrado para una región del país. Esta proceso de migración interno está asociado con el rápido avance de la frontera agrícola por colonos mestizos hacía las Regiones Autónomas- principalmente en los municipios de Bocana de Paiwas, Muelle de los Bueyes, El Rama y Nueva Guinea, causando una fuerte presión sobre los recursos naturales (incluida la deforestación y la degradación de bosques), conflictos interétnicos con las comunidades indígenas y afrodescendientes por la tenencia y uso de tierras y una acelerada mestización de la población caribeña (Frühling, González, \& Buvollen, 2007). El tráfico y consumo de drogas dentro de la población caribeña ha proliferado desde los 199os, penetrando significativamente a las comunidades indígenas y afrodescendientes, en donde están causando todo tipo de violencia y destruyendo el capital social comunitario (PNUD, 2005). El mal uso de los pocos fondos asignados y el recibo de por la concesión ilegal de permisos de explotación de recursos naturales son dos dinámicas fundamentales de la corrupción existente en los Concejos y Gobiernos Regionales Autónomos. De allí que el 74 por ciento de la población considere que la corrupción es un gran problema en el Gobierno Regional (Ibíd.). En este período se han tenido desastres naturales como huracanes (Joan en 1988, César en 1996, Mitch en 1998, Beta en 2005, Félix en 2007 e Ida en 2009), inundaciones, sequías e incendios forestales.

Actualmente, un alto porcentaje de esta población tiene claro que las autoridades autonómicas electas no han funcionado bien- 69.9 por ciento, que el Gobierno Central de Managua no ha querido apoyar la Autonomía- 66 por ciento y que los partidos políticos nacionales tienen mucha influencia en el proceso autonómico del Caribe65.9 por ciento (PNUD, 2005). En este último caso, el 75.7 por ciento de la población caribeña tiene la percepción que los Concejales Regionales le hacen demasiado caso a los partidos políticos nacionales que a la gente que los eligió (ibíd.). Desde el inicio de la implementación del Estatuto de Autonomía, el gobierno central y la clase política del Pacífico han invertido conscientemente esfuerzos para debilitar y disminuir los alcances del régimen de autonomía, han asumido como natural la subordinación que la autonomía- a través de los consejos y gobiernos regionales autónomos deben tenerles y han considerado en la práctica a las Regiones Autónomas como una reserva de recursos naturales para la explotación conforme al mejor interés "nacional" (Ibíd.). En este corto andar de la autonomía, las políticas públicas impulsadas por los gobiernos centrales han sido de corte centralista, desarrollista y etnocéntrica.

A pesar de esta problemática, causas y efectos, la Autonomía en la Costa Caribe tiene sus avances importantes. Mediante una fuerte inversión de esfuerzos de unidad, concertación e incidencia, los pueblos indígenas y afrodescendientes de la Costa Caribe nicaragüense han logrado ampliar el marco jurídico de reivindicaciones de sus derechos históricos, especialmente colectivos. Una serie de leyes promulgadas en este 
período han logrado superar los vacios e incongruencias presentes en el Estatuto de Autonomía. Entre estas leyes están la Ley número 162 o Ley de uso oficial de las Lenguas de las Comunidades de la Costa Atlántica de Nicaragua (aprobada en 1996), la Ley número 445 o Ley del Régimen de Propiedad Comunal de los pueblos indígenas y Comunidades Étnicas de las Regiones Autónomas de la Costa Atlántica de Nicaragua y de los Ríos Bocay, Coco, Indio y Maíz (aprobada en 2002) y el reglamento de la Ley número 28 o Estatuto de la Autonomía de las Regiones Autónomas de la Costa Atlántica (aprobado en 2003). En el ámbito de las Regiones Autónomas, los propios actores regionales han creado, participativamente y por consenso, políticas públicas regionales de avanzada en el contexto de Latinoamérica, que de igual manera llenan los vacíos y superan las incongruencias del Estatuto de Autonomía. Entre las principales políticas regionales están los modelos, los de Salud Autonómico Regional de la RAAN y RAAS y el Sistema Educativo Autonómico Regional (SEAR). Estas políticas regionales, aprobadas por los Consejos Regionales Autónomos en 1997, han sido incorporadas a la Ley número 423 o Ley General de Salud (aprobada en 2002) y la Ley número 582 o la Ley General de Educación (aprobada en el 2006). Otros avances importantes es el establecimiento de dos universidades regionales: la Universidad de las Regiones Autónomas de la Costa Caribe Nicaragüense (URACCAN) y la Bluefields Indian and Caribbean University (BICU) . De igual manera, las Regiones Autónomas cuentan con varias organizaciones no gubernamentales (ONG), para el impulso del desarrollo regional. Entres las principales ONG con fuerte orientación al fortalecimiento de la autonomía están: FADCANIC, CEDEHCA, ADEPHCA, AMICA, PANA PAN y los movimientos de mujeres.

En el balance entre logros, carencias y debilidades, la Autonomía Regional presenta retos fundamentales para su fortalecimiento y desarrollo. Los principales retos para el avance significativo de la Autonomía Regional son (i) el fortalecimiento de las capacidades de gestión e incidencia dentro de cada pueblo indígena y afrodescendiente para el impulso de su plan de vida autonómico tanto ante el Estado, la sociedad civil, la empresa privada como antes los mismos Consejos y Gobiernos Regionales; (ii) el establecimiento y fortalecimiento de espacios democráticos permanentes conjuntos entre los pueblos indígenas y afrodescendientes que construyan una unidad mínima adecuada de visión y actuar alrededor del avance práctico de la Autonomía Regional en todos sus ámbitos y la ampliación en la reivindicación de derechos históricos; (iii) el fortalecimiento de la institucionalidad autonómica, especialmente en los niveles técnicos y de transparencia social tanto de los Consejos y Gobiernos Regionales como de las instituciones autonómicas de sociedad civil y de los propios pueblos indígenas y afrodescendientes; (iv) la continua sensibilización de la sociedad multiétnica Caribeña en general sobre los valores e importancia del régimen de autonomía, particularmente en sus posibilidades de construcción de la interculturalidad, la ciudadanía intercultural, el buen vivir y el desarrollo con identidad. El mayor reto de todos es la continua construcción de unidad en la diversidad étnica de los pueblos indígenas y afrodescendientes para una eficaz movilización política para la defensa y avance de la Autonomía 
Regional Indígena y Afro Descendiente, en un contexto actual de consolidación del bipartidismo, grupos de interés económicos y la polarización político- partidaria. Tomando los ejemplos de la historia, la Autonomía Regional sólo se consolidará con la permanente e incesante lucha de los pueblos indígenas y afrodescendientes por el reconocimiento y ejercicio efectivo de sus derechos históricos, donde una importante parte ya están consignados en el Estatuto de Autonomía.

\section{El reto educativo de los pueblos indígenas y afrodescendientes}

\section{La situación educativa en Nicaragua}

El rezago educativo es un indicador importante de exclusión social y pobreza en Nicaragua. Mientras los no pobres tienen una incidencia promedio de analfabetismo del 10.5 por ciento, los pobres y pobres extremos padecen en un 27.8 por ciento y 37.3 por ciento el analfabetismo (INIDE., 2007). La educación promedio acumulada entre no pobres, pobres y pobres extremos es de 7.1 años, 3.7 años y 2.7 años respectivamente (Ibíd.). Las tasas brutas de matrícula en los niveles de Educación Secundaria y Superior demuestran una brecha severa de ingreso de los pobres, pero más de los pobres extremos. En el cuadro de abajo detalla esta realidad brecha severas en Educación Secundaria y universitaria de los pobres y pobres extremos.

\begin{tabular}{lcccc}
\hline $\begin{array}{c}\text { NIVEL } \\
\text { EDUCATIVO }\end{array}$ & NO POBRES & POBRES & $\begin{array}{c}\text { POBRES } \\
\text { EXTREMOS }\end{array}$ & NACIONAL \\
\hline PRIMARIA & $106.6 \%$ & $111.0 \%$ & $103.7 \%$ & $109.1 \%$ \\
\hline SECUNDARIA & $87.8 \%$ & $32.1 \%$ & $18.0 \%$ & $70.0 \%$ \\
\hline UNIVERSITARIA & $35.1 \%$ & $2.0 \%$ & $0.5 \%$ & $23.0 \%$ \\
\hline Fuente: (INIDE., 2007) & & & &
\end{tabular}

También se puede observar las brechas en tasas brutas de matrícula en los niveles de Educación Pre- escolar, Primaria y Secundaria entre las dos Regiones Autónomas con respecto al promedio nacional. Con la excepción de las RAAN en los niveles de pre- escolar y primaria, en la RAAS y en el nivel de Educación Secundaria existe una amplia brecha de ingreso a la educación formal. A continuación se presenta un cuadro de información de tasas brutas de matrícula en los niveles de Educación Pre-escolar, Primaria y Secundaria en la RAAN y RAAS con respecto al promedio nacional.

\begin{tabular}{lllc}
\hline \multicolumn{1}{c}{ INDICADOR } & RAAN & RAAS & NACIONAL \\
\hline Tasa bruta de matrícula pre- escolar & $36.8 \%$ & $14.4 \%$ & $32.0 \%$ \\
\hline Tasa bruta de matrícula primaria & $152.0 \%$ & $96.7 \%$ & $111.9 \%$ \\
\hline Tasa bruta de matrícula secundaria & $37.1 \%$ & $27.4 \%$ & $58.5 \%$ \\
\hline Fuente: (PNUD, 2005) & & &
\end{tabular}

Las brechas educativas en las Regiones Autónomas se puede también observar a nivel municipal en el siguiente cuadro. Con la excepción de Puerto Cabezas, Bluefields 
y Corn Island, el resto de los municipios de las Regiones Autónomas tienen niveles de analfabetismo superiores al promedio nacional. La asistencia escolar de la población mayor de 5 años es inferior en 13 de los 20 municipios de las Regiones Autónomas con respecto al promedio nacional. Ambas Regiones Autónomas tienen un promedio inferior al promedio nacional en asistencia escolar.

\begin{tabular}{|c|c|c|c|}
\hline \multirow[t]{2}{*}{ MUNICIPIO } & \multicolumn{2}{|c|}{$\begin{array}{l}\text { ANALFABETISMO } \\
\text { Mayores de } 6 \text { años }\end{array}$} & \multirow{2}{*}{$\begin{array}{c}\text { ASISTENCIA } \\
\text { ESCOLAR } \\
\text { Mayores de } 5 \text { años } \\
\%\end{array}$} \\
\hline & TOTAL & $\%$ & \\
\hline RAAN & 106,244 & 42.21 & 26.98 \\
\hline Waspam & 13,251 & 35.74 & 37.15 \\
\hline Puerto Cabezas & 12,825 & 23.61 & 42.76 \\
\hline Prinzapolka & 6,892 & 55.27 & 31.52 \\
\hline Bonanza & 5,468 & 36.62 & 33.13 \\
\hline Rosita & 8,086 & 44.16 & 26.43 \\
\hline Siuna & 26,773 & 52.38 & 14.65 \\
\hline Waslala & 19,826 & 50.29 & 13.64 \\
\hline Mulukukú & 13,123 & 54.62 & $s / d$ \\
\hline RAAS & 120,279 & 47.35 & 23.26 \\
\hline La Cruz de Río Grande & 11,389 & 62.94 & 16.15 \\
\hline Desembocadura de Río Grande & 1,195 & 40.29 & 42.84 \\
\hline El Tortuguero & 11,374 & 66.03 & 16.43 \\
\hline Laguna de Perlas & 2,897 & 32.58 & 38.47 \\
\hline Kukra Hill & 2,932 & 40.63 & 22.67 \\
\hline Bluefields & 8,041 & 20.55 & 39.00 \\
\hline Corn Island & 749 & 13.23 & 36.19 \\
\hline El Rama & 18,764 & 43.17 & 18.58 \\
\hline Nueva Guinea & 37,639 & 66.49 & 22.50 \\
\hline Muelle de los Bueyes & 6,943 & 36.85 & 20.64 \\
\hline Paiwas & 13,188 & 51.30 & 13.95 \\
\hline El Ayote & 5,168 & 50.51 & $s / d$ \\
\hline RAAN y RAAS & 226,523 & 44.79 & 24.79 \\
\hline Resto de Nicaragua & 833,359 & 21.37 & 33.81 \\
\hline Nicaragua & $1,059,882$ & 24.06 & 32.89 \\
\hline
\end{tabular}

Fuente: (Williamson Cuthbert \& Fonseca Duarte, 2007) 
En el nivel de Educación Superior, existen 52 instituciones de Educación Superior legalmente reconocidas por el Consejo Nacional de Universidades (CNU) en el país ${ }^{[2]}$. En este nivel, la matrícula total en el 2007 fue de 180, oo estudiantes, correspondiendo el 60 por ciento de la matrícula a Instituciones de Educación Superior (IES) privadas y el 40 por ciento a las diez IES del CNU, que reciben financiamiento Estatal (López Segrega, Brock, \& Dias Sobrinho, 2009). En el 2008, las universidades del CNU tuvieron una matrícula total de 98.916 estudiantes, en sus ofertas de preparatoria con 898 estudiantes, técnico superior con 4,067, licenciaturas y/o ingenierías con 79,501, postgrados con 4,530 y educación continua con 9,920. De este total de estudiantes, incluyendo los de educación continua, el 16.49 por ciento procede de las dos Regiones Autónomas. Las dos universidades caribeñas, URACCAN y BICU, totalizan el 93.20 por ciento de esta matrícula procedente de las dos Regiones Autónomas y el 16.35 por ciento de la matrícula total del CNU. En el cuadro siguiente se presentan además datos sobre graduación y becados internos.

\begin{tabular}{|c|c|c|c|c|c|c|}
\hline IES & TOTAL & RAAN & RAAS & $\begin{array}{c}\text { ESTUDIANTES } \\
\text { PROCEDENTES } \\
\text { DE LA RAAN y } \\
\text { RAAS }\end{array}$ & INTERNO & $\begin{array}{c}\text { GRA- } \\
\text { DUACIÓN }\end{array}$ \\
\hline $\begin{array}{l}\text { UNAN- } \\
\text { León }\end{array}$ & 16,842 & 202 & 122 & 324 & 919 & 1,455 \\
\hline $\begin{array}{l}\text { UNAN- } \\
\text { Managua }\end{array}$ & 27,542 & 75 & 127 & 202 & 744 & 3,102 \\
\hline UCA & 9,589 & 18 & 34 & 52 & 70 & 913 \\
\hline UPOLI & 11,912 & 118 & 134 & 252 & 0 & 837 \\
\hline UNI & 11,405 & 64 & 56 & 120 & 117 & 1,022 \\
\hline UNA & 3,490 & 63 & 84 & 147 & 335 & 372 \\
\hline EIAG-Rivas & 640 & 3 & 6 & 9 & 185 & 101 \\
\hline $\begin{array}{l}\text { UCATSE- } \\
\text { Estelí }\end{array}$ & 1,325 & 2 & 1 & 3 & 0 & 136 \\
\hline URACCAN & 8,951 & 1920 & 1,610 & 8,599 & 245 & 602 \\
\hline $\mathrm{BICU}$ & 7,220 & 1649 & 3,644 & 6,608 & 644 & 972 \\
\hline TOTAL & 98,916 & 4,114 & 5,818 & 16,316 & 3,259 & 9,512 \\
\hline
\end{tabular}

Fuente: Datos CNU en www.cnu.edu.ni.

\section{La situación educativa de los pueblos indígena y afrodescendientes}

Confirmado por la poca información disponible, los pueblos indígenas tienen el mayor rezago educativo entre la población nicaragüense. Las tasas de analfabetismo de los

[2] $\mathrm{Al}_{31}$ de Diciembre de 2008. 
pueblos indígenas de las Regiones Autónomas están por encima del promedio nacional, cuya tasa es del 24.06 por ciento. Las tasas de analfabetismo en el pueblo indígena rama es del 35 por ciento, en el pueblo indígena sumo- mayangna es 33 por ciento y en el pueblo miskito es 28.7 por ciento (Delgadillo, 2007). La población afrodescendiente tienen tasas inferiores al promedio nacional, teniendo los garífuna una tasa del 21.9 por ciento y los kriol del 8.1 por ciento de analfabetismo (Ibíd.). Según Jamieson, los principales factores de este rezago educativo de los pueblos indígenas son el deficitario ingreso a la Educación Primaria que en el mejor de los casos llega a sexto grado, pero peor es el ingreso a una primaria cultural y lingüísticamente relevante (1999). Las tasas de deserción, rotación de maestros y maestras por razones de bajos salarios y empirismo entre docentes, son otros factores que inciden grandemente en el rezago educativo de los pueblos indígenas (Jamieson, 1999).

La Educación Intercultural Bilingüe, impulsada por el Estado nicaragüense a través del Programa de Educación Bilingüe Intercultural (PEBI), para atender las necesidades socio lingüísticas de educación de los pueblos indígenas y afrodescendientes de las Regiones Autónomas, ha estado siempre limitada en sus alcances. El PEBI, establecido dentro del Ministerio de Educación, ha tenido tres sedes principales de operaciones para los dos pueblos indígenas (miskito y sumo- mayangna) y uno afro descendiente (kriol) cubiertos. El PEBI-Miskitu tiene su sede principal en Bilwi, el PEBI- Sumo Mayangna en Rosita y el PEBI- kriol en Bluefields. En el estudio más reciente sobre el PEBI, en la RAAN el programa cubre de preescolar hasta cuarto grado para los pueblos indígenas miskitu y sumu/mayangna, mientras que en la RAAS el PEBI cubre de preescolar hasta sexto grado para los kriol (FOREIBCA, 2000). En el año 2001, la cobertura del PEBI alcanzaba a un total de 21,958 estudiantes, ubicados en 213 escuelas y atendidos por 778 docentes (Ibíd.). El grupo lingüístico miskitu representa la mayor cantidad de estudiantes y alumnas con una población escolar de 16,207estudiantes, seguido del kriol con 3,125 estudiantes, y del sumu- mayangna con 1,898 estudiantes (Ibíd.). Los cuadros siguientes reflejan los alcances del PEBI, conforme información disponible.

\begin{tabular}{llccc}
\hline \multirow{2}{*}{ REGIÓN } & \multirow{2}{*}{ PROGRAMA PEBI } & \multicolumn{3}{c}{ TOTAL } \\
\cline { 3 - 5 } & & ESCUELAS & DOCENTES & ESTUDIANTES \\
\hline RAAN & Miskitu & 153 & 450 & 16,207 \\
\hline RAAN & Sumo- Mayangna & 38 & 145 & 1,898 \\
\hline RAAS & Creole & 16 & 145 & 3,125 \\
\hline RAAS & Miskitu & 6 & 38 & 728 \\
\hline & Total & $\mathbf{2 1 3}$ & $\mathbf{7 7 8}$ & $\mathbf{2 1 , 9 5 8}$ \\
\hline
\end{tabular}

Desde la promulgación de la Ley número 582 o Ley General de Educación, la Educación Intercultural Bilingüe (EIB) se reconoce como parte del Sub- Sistema Educativo Autonómico Regional (SEAR). El avance de la EIB y el SEAR ha estado limitado por dos factores principales. El primer factor es la débil capacidad administrativa 
de los Consejos y Gobiernos Regionales. Estas instancias autonómicas no han sido efectivas en el aprovechamiento de proyectos de fortalecimiento del SEAR, que han incluido la elaboración de libros de textos y su validación. El SEAR, como resultados de dos proyectos (FOREIBCA y SAHWANG), ya cuenta con currículos de EIB transformado para la Educación Primaria y la formación docente. Han quedado pendientes completar la elaboración y validación de los textos educativos. El segundo factor es voluntad política de las autoridades regionales para asumir propositivamente la disposición del Gobierno Central actual, de regionalizar el SEAR. Las autoridades regionales han manifestado no estar listos para asumir dicha descentralización. En este contexto, el Ministerio de Educación ha estado implementando en los dos últimos años sus currículos y directrices monoculturales. El SEAR se encuentra entonces en un impase administrativo.

Los pueblos indígenas y afrodescendientes también tienen severas brechas de ingreso a la Educación Superior. En el primer semestre de 2010, las universidades caribeñas tienen una matrícula total entre ambas de 4,218 estudiantes de pueblos indígenas y afrodescendientes. La matrícula de pueblos indígenas y afrodescendientes representa el 60.76 por ciento de la matrícula total de las dos universidades, siendo de 25.43 por ciento en la matricula total de URACCAN y 52.46 por ciento en la matricula total de BICU. De la matrícula total de pueblos indígenas y afrodescendientes de las dos universidades, a URACCAN le corresponde el 36.51 por ciento y a BICU el 63.49 por ciento. El siguiente cuadro detalla la matrícula por pueblo.

\begin{tabular}{lccccccc}
\hline & \multicolumn{6}{c}{ MATRÍCULA POR ETNICIDAD, PRIMER SEMESTRE 2010 } \\
\cline { 2 - 7 } UNIVERSIDAD & MISKITO & $\begin{array}{c}\text { SUMO- } \\
\text { MAYANGNA }\end{array}$ & RAMA & KRIOL & $\begin{array}{c}\text { GARÍ- } \\
\text { FUNA }\end{array}$ & $\begin{array}{c}\text { SUB- } \\
\text { TOTAL }\end{array}$ & $\begin{array}{c}\text { SUB- } \\
\text { TOTAL } \\
\text { MESTIZO }\end{array}$ \\
\hline URACCAN & 885 & 326 & 21 & 274 & 34 & 1,540 & 4,515 \\
\hline BICU & 1,595 & 94 & 15 & 909 & 65 & 2,678 & 2,427 \\
\hline TOTAL & $\mathbf{2 , 4 8 0}$ & $\mathbf{4 2 0}$ & $\mathbf{3 6}$ & $\mathbf{1 , 1 8 3}$ & $\mathbf{9 9}$ & $\mathbf{4 , 2 1 8}$ & $\mathbf{6 , 9 4 2}$ \\
\hline
\end{tabular}

Fuente: Datos suministrados por la Oficina de Registro de la URACCAN y la Secretaría General de BICU.

En las otras universidades del CNU, no existe en sus estadísticas la disgregación por etnicidad. Por ello, los pueblos indígenas y afrodescendientes no pueden ser visibilizados en su matrícula. Sin embargo, se debe mencionar como caso excepcional de las universidades del Pacífico, a la Universidad Nacional Autónoma de Nicaragua (UNAN) con sede en la ciudad de León. La UNAN- León tiene un programa de becas para estudiantes de las Regiones Autónomas, establecido en el 2005 por el entonces Rector Rigoberto Sampson. Al 2009, este programa denominado: "Programa de Acompañamiento Académico para Estudiantes de la Costa Caribe” ha cubierto a 155 
estudiantes. No se cuenta con la disgregación étnica de estos estudiantes. A continuación el detalle de estudiantes por año de ingreso.

\begin{tabular}{|c|c|c|c|}
\hline \multirow{2}{*}{$\begin{array}{c}\text { AÑO } \\
\text { LECTIVO }\end{array}$} & \multicolumn{2}{|c|}{ MATRÍCULA } & \multirow{2}{*}{ TOTAL } \\
\hline & RAAN & RAAS & \\
\hline 2005 & 20 & 28 & 48 \\
\hline 2006 & 29 & 12 & 41 \\
\hline 2006 & 29 & 12 & 41 \\
\hline 2007 & 71 & 58 & 129 \\
\hline 2008 & 88 & 51 & 139 \\
\hline 2009 & 96 & 59 & 155 \\
\hline
\end{tabular}

Fuente: Presentación hecha por la Licda. Marta Munguía en el Primer Foro Interuniversitario del Caribe realizado del 17 al 19 de Marzo de 2009 en Costa Rica.

Este programa contempla los siguientes servicios para los estudiantes beneficiarios:

- Internado y atención médica, odontológica, psicológica, etc.

- Profesores tutores sensibilizados con el programa.

- Profesores de formación personal brindan atención especial a estudiantes, para facilitar su adaptación a vida universitaria.

- Estudiantes de últimos años como parte de sus prácticas profesionales brindan asesoría académica a estudiantes del Año de Estudios Generales (AEG) en matemática, computación, comunicación y lenguaje.

- Conformación de estudiantes monitores en el I año (AEG), por municipio y por componente curricular.

- Programa cuenta con la ayuda Económica del "Servicio de relaciones internacionales y cooperación, del ayuntamiento de Vilafranca del Panedes - España”, para los estudiantes de la RAAN.

- Entrega a estudiantes de la RAAN de: estuches de cirugía menor, estetoscopio, tensiómetros y materiales de reposición periódica, ordenes de fotocopias y viáticos de transporte.

- Estudiantes de segundo año son atendido por profesores tutores en cada carreras. 


\section{La experiencia de la URACCAN en la atención estudiantes indígenas y afrodescendientes}

\section{Breve reseña histórica}

La URACCAN es una larga aspiración de los pueblos indígenas, afrodescendientes y mestizos costeños hecha realidad. Durante los años 70 un grupo de ciudadanos y ciudadanas de la Costa Caribe se unieron e impulsaron una campaña para que la Universidad Nacional Autónoma de Nicaragua (UNAN), estableciera en la Región Caribe una sede universitaria. El resultado fue el desarrollo de una oferta temporal de cursos de Ciencias de la Educación, que en los años 80 se establece a un Programa Universitario de Educación a Distancia (PRUEDIS). Los estudiantes de estas iniciativas no tuvieron la oportunidad de culminar sus estudios a pesar de los múltiples esfuerzos realizados en estos períodos. Con el apoyo de la cooperación internacional y recursos propios de los fundadores, URACCAN inicia operaciones en 1995 con los 120 estudiantes de ambas Regiones Autónomas procedentes del PRUEDIS. La gestión del proyecto universitario inicia en 1990 cuando se presenta al Consejo Nacional de Universidades (CNU), sus documentos constitutivos. Su autorización por parte del CNU se obtuvo el 3 de Marzo de 2002, lo que permitió que obtuviese su personería jurídica de parte de la Asamblea Nacional mediante decreto número 602, publicado en La Gaceta, Diario Oficial, número 104, del 3 de Junio de 1993. En 1996, después de una intensa lucha, incidencia y negociación política liderada por sus fundadores, reflejada en la Ley número 218 o "Ley para la Asignación del Presupuesto Universitario a Inclusión de las Universidades BICU y URACCAN en la Ley de Autonomía de las Instituciones de Educación Superior, la URACCAN se integra al CNU y obtiene financiamiento Estatal.

La URACCAN es una universidad comunitaria intercultural. La universidad es un espacio establecido por líderes indígenas, afrodescendientes y mestizos Costeños de las Regiones Autónomas de Nicaragua para hacer un ejercicio efectivo del derecho de sus pueblos a una Educación Superior, que forme integralmente con elevada calidad y valores ético y morales que promueva la unidad multiétnica para el fortalecimiento de la Autonomía Regional. Su carácter comunitario está determinado por el papel central del acompañamiento a los procesos de autogestión comunitaria para la profundización de la Autonomía. Así, en el 2002, los Consejos Regionales Autónomos reafirman a la URACCAN como una universidad comunitaria e intercultural, la declara Patrimonio de los pueblos indígenas y Comunidades Étnicas de las Regiones Autónomas y le concede la calidad de Universidad Comunitaria de las Regiones Autónomas. La Ley General de Educación (Ley número 582) aprobada, formaliza a nivel nacional el carácter comunitario de URACCAN, definiéndola de interés público regional (artículo 49). 


\section{El Carácter de la Universidad}

En su Plan Estratégico 2008- 2012, la comunidad universitaria de URACCAN, junto a las comunidades, organizaciones indígenas y afrodescendientes, sociedad civil, empleadores, iglesias y autoridades autonómicas- definió como su visión institucional: "Ser líder en el paradigma de universidad comunitaria intercultural en el ámbito nacional e internacional, que acompaña procesos de desarrollo con identidad de los pueblos indígenas, mestizos, comunidades étnicas y afrodescendientes para la promoción de la ciudadanía intercultural". En las Regiones Autónomas, la ciudadanía intercultural es el marco de ejercicio efectivo de los derechos constitucionales y autonómicos de las mujeres y hombres (niñez, jóvenes, adultos y tercera edad) de los pueblos indígenas, afrodescendientes y comunidades étnicas. La promoción de ciudadanía intercultural es un proceso de desarrollo de capacidades de participación activa, gestionaría y de diálogo intercultural para la transformación del entorno de exclusión, inequidad y empobrecimiento de los pueblos indígenas y afrodescendientes.

La misión de su quehacer es la: "formación de recursos humanos, con conocimientos y capacidades científico- técnica, actitudes humanistas, sentido del emprendimiento y la innovación, que contribuyan al fortalecimiento del Sistema Autonómico Regional y del país. Desde la aprobación por la Asamblea Nacional del Estatuto de la Autonomía de las Regiones Autónomas de la Costa Atlántica (Ley No. 28), el 2 de Septiembre de 1987, los pueblos indígenas y afrodescendientes de la Costa Caribe nicaragüense disponen de un régimen jurídico que reivindica sus derechos individuales y colectivos históricos, en los ámbitos políticos, sociales, económicos y culturales.

\section{Su alcance organizacional}

La URACCAN es una de las principales instituciones de las Regiones Autónomas de la Costa Caribe, tanto por su cobertura como por su dimensión. Al iniciar el 2010, la universidad cubre geográficamente las dos Regiones Autónomas, mediante cuatro recintos y cuatro extensiones universitarias. En la RAAN, la URACCAN cuenta con recintos en las cabeceras municipales de Bilwi y Siuna. Estos disponen a su vez de extensiones universitarias para ampliar la cobertura de sus programas. El Recinto de Bilwi tiene extensión en la cabecera municipal de Waspam. El Recinto Las Minas tiene a su vez extensiones universitarias en las cabeceras municipales de Rosita, Bonanza y Waslala. En la RAAS, URACCAN tiene recintos en Bluefields y Nueva Guinea. Desde los recintos y extensiones universitarias la universidad dirige sus funciones y programas de docencia, investigación, extensión social y comunitaria e internacionalización. Estas funciones y programas se desarrollan permanentemente en ocho de los veinte municipios que componen las Regiones Autónomas. Estos municipios representan el 61.34 por ciento de la población total de las Regiones Autónomas, 85.37 por ciento de la población total de la RAAN y 36.7 por ciento de la población total de la RAAS (INEC, 2006). Por su presencia étnica, estos ocho municipios concentran el 80.09 por 
ciento de la población total indígena ( $77.75 \%$ miskitu, 93.99\% sumo mayangna y $100 \%$ rama- y el $66.57 \%$ de la población total afrodescendiente, $77.11 \%$ la kriol y $6.99 \%$ de la garífuna (URACCAN). El proceso social y político de la construcción de la autonomía en las Regiones Autónomas de la Costa Caribe nicaragüense. Capítulo II del informe de desarrollo humano de la Costa Caribe ¿Nicaragua asume su diversidad? Regiones Autónomas, 2004).

La URACCAN cuenta con cinco institutos y 2 centros en áreas claves para el desarrollo de la Autonomía Regional. Los institutos son el Instituto de Recursos Naturales, Medio Ambiente y Desarrollo Sostenible (IREMADES), el Instituto de Promoción e Investigación Lingüística y Revitalización Cultural (IPILC), el Instituto de Estudios y Promoción de la Autonomía (IEPA), el Instituto de Medicina Tradicional y Desarrollo Comunitario (IMTRADEC) y el Instituto de Comunicación Intercultural (ICI). Los centros son el Centro de Estudios e Información de la Mujer Multiétnica (CEIMM) y el Centro de Información Socio Ambiental (CISA). Desde los recintos y extensiones, estos institutos y centros tienen a su cargo el liderazgo técnico de los procesos de investigación, extensión social y comunitaria en sus campos. La Universidad también se víncula con la comunidad a través de estaciones de radios en las cabeceras municipales de Siuna, Rosita, Bluefields y Laguna de Perlas y en la comunidad indígena miskita de Sahsa, municipio de Puerto Cabezas. Estas radio emisoras comunitarias están bajo la dirección del ICI, al igual que programas de TV cables en Bilwi y Bluefields. Así también, la Universidad cuenta con fincas académicas en los recintos de Bilwi, Siuna y Nueva Guinea. En el recinto Bluefields se dispone de un hotel escuela y en el recinto Nueva Guinea de un pequeño museo arqueológico. Se debe mencionar que prácticamente desde su inicio de actividades en 1995, URACCAN tiene en la capital, Managua, una oficina de representación orientada a la gestión, incidencia y trabajo en red. La presencia de la Universidad, y de sus instancias, se puede observar en la imagen siguiente. 


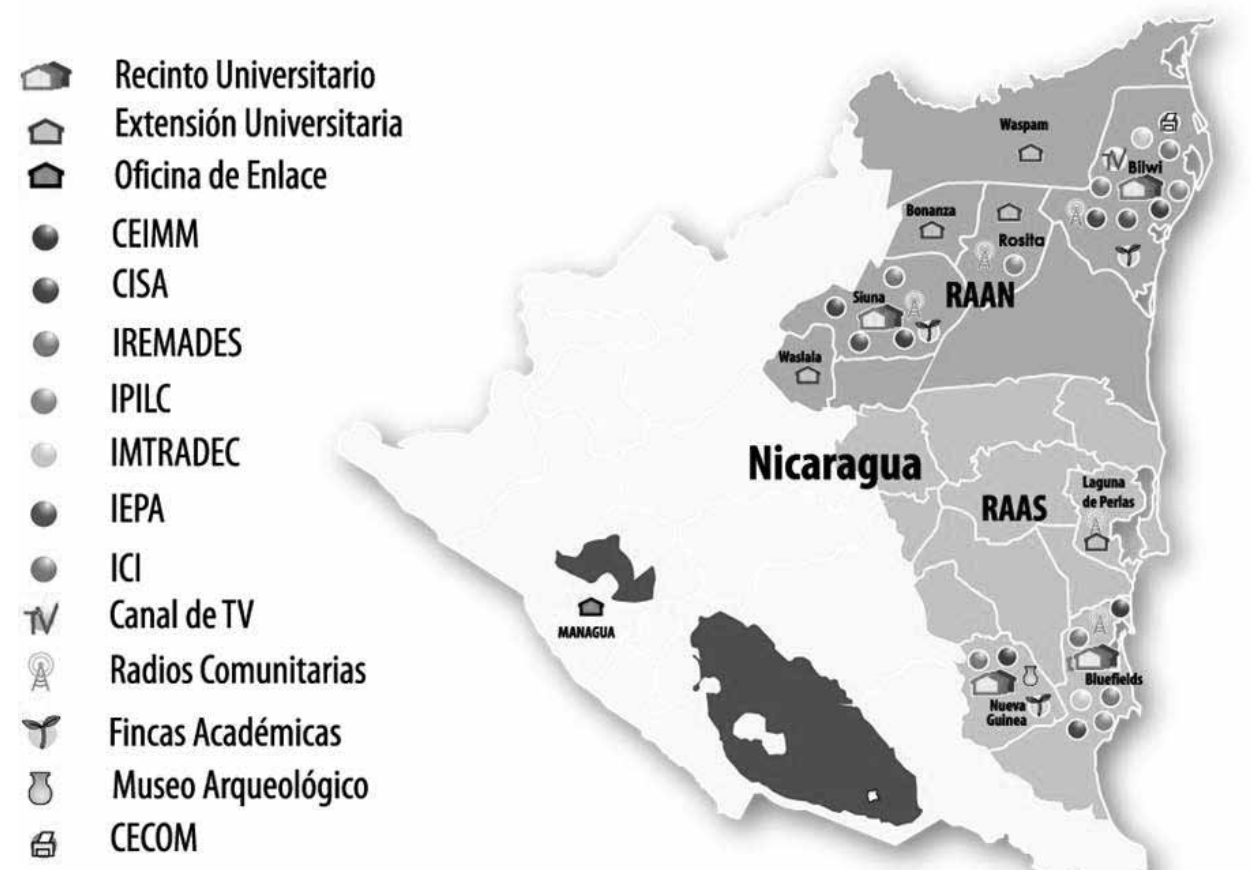

En el 2009, la comunidad universitaria de la URACCAN constó de 14,168 estudiantes y 827 trabajadores en su personal. Los estudiantes estuvieron distribuidos así: 173 en 7 cursos de postgrado; 3,766 estudiantes en 26 cursos de pregrado y 10,229 estudiantes en cursos de educación continua, que incluyen los 6,530 estudiantes de 14 diplomado y 3,699 estudiantes de 76 cursos talleres, capacitaciones y foros. El 77 por ciento (10,520 estudiantes) de la población estudiantil fue mujer. Como parte de la oferta de cursos 2009, la URACCAN ha desarrollado un Diplomado Comunitario en Desarrollo Integral de la Niñez Nicaragüense a 6,049 educadoras, madres y padres voluntarios y líderes comunitarios de 66 municipios del país en alianza con el Ministerio de la Familia (MIFAMILIA) y con el auspicio del Banco Interamericano de Desarrollo (BID). En el 2010, URACCAN inició con una matrícula de 6,055 estudiantes. En cuanto al personal institucional, el recinto Bilwi cuenta con 276 trabajadores, el recinto Siuna con 166 trabajadores, el Recinto Bluefields con 225 trabajadores, el Recinto Nueva Guinea con 101 trabajadores y la Oficina de Enlace en Managua con 39 trabajadores. Del personal total de URACCAN en el 2009, el 49 por ciento (406 trabajadores) fue de tiempo completo y el 51 por ciento (421) de contrato por tiempo determinado. El personal vinculado a las actividades académicas es de 526 personas, el 64 por ciento del personal institucional total. De este total, 134 personas están vinculadas a la investigación en diferentes áreas del conocimiento. La Universidad inició en 1995 con una matrícula total de 751 estudiantes distribuidos en 3 recintos: Recinto Bilwi con 
203 estudiantes; Recinto Siuna, con 186 estudiantes y el Recinto Bluefields, con 362 estudiantes y 21 docentes, 7 por recinto (URACCAN, Informe de Gestión 1994- 2002. Hacia la autonomía por la universidad, 2003). El personal administrativo era de 15 trabajadores aproximadamente.

Como una institución de Educación Superior joven, la URACCAN ha ido obtenido buenos frutos en su quehacer académico. En el 2009, la Universidad egresó a 506 estudiantes ( 56 estudiantes de postgrado, 437 estudiantes de pregrado y 13 estudiantes de la Escuela de Liderazgo), graduó a 395 estudiantes (58 de postgrado, 324 de pregrado y 13 de la Escuela de Liderazgo), concluyeron 361 investigaciones (24 realizadas por docentes, 46 por estudiantes de postgrado y 291 por estudiantes de pregrado) y se publicaron 75 trabajos (incluidos 1 libro, 16 artículos técnicos en revistas no indexadas y 2 revistas científicas). Al mismo tiempo, docentes y estudiantes de la Universidad participaron en 66 distintos eventos académicos, incluyendo 6 eventos internacionales, y lograron presencia 200 trabajados investigativos en diferentes eventos como jornadas científicas interuniversitarias, exposiciones científicas, congresos científicos y foros, entre otros. En el primer trimestre de 2010, se obtuvo un registro de 261 estudiantes egresados y 60 graduados, todos en el nivel de pregrado. Desde sus inicios, la URACCAN ha graduado a 4,535 estudiantes. Estos productos universitarios se logran aprovechando los pocos recursos disponibles.

La URACCAN tiene tres fuentes de financiamiento para su quehacer institucional: la autogestión de fondos propios, la asignación presupuestaria estatal y fondos proporcionados por la cooperación internacional. Cada una ha tenido una importancia relativa y complementaria en el desarrollo de la Universidad, y en el cumplimiento de su misión y visión. Los fondos propios proporcionados por el grupo de fundadores conllevó a la constitución de la Asociación Pro URACCAN, la elaboración participativa del proyecto institucional de la Universidad, la movilización para la aprobación del proyecto de la universidad por parte del Consejo Nacional de Universidades (CNU), la obtención de personería jurídica sin fines de lucro como Asociación URACCAN, para poder manejar fondos externos y la gestión de los primeros proyectos con la cooperación internacional.

Los fondos proporcionados por los fundadores vía aportes salariales y de otros ingresos, hipotecas y otros activos también contribuyeron en el inicio de las clases, sufragando gastos de docencia y materiales didácticos. El 13 de Abril de 1996 la Asamblea Nacional aprueba la Ley número 218 o "Ley para la asignación del presupuesto universitario e inclusión de las universidades BICU y URACCAN en la Ley de Autonomía de las Instituciones de Educación Superior" a partir del cual la universidad comenzaría a recibir un porcentaje del seis por ciento del Presupuesto General de la República, asignado a las universidades miembros del CNU. En el 2009, el porcentaje recibido por la URACCAN fue de 3.16 por ciento, equivalente a $C \$ 58,988,580.56$, es decir, US $\$ 3.046$ millones aproximadamente. Este porcentaje ha ido incrementándose 
en la medida que el CNU ha aprobado recortes a las universidades privadas que existen dentro de su seno, principalmente la Universidad Centroamericana (UCA) y la Universidad Politécnica de Nicaragua (UPOLI). Esta partida presupuestaria asignada por el Estado nicaragüense cubre principalmente la planilla de la Universidad (un $75 \%$ aproximadamente del total asignado) y la operación de sus recintos y extensiones. Por otro lado, los fondos de cooperación externa aprobados a través de proyectos y programas están destinados al empoderamiento de los distintos pueblos indígenas y afrodescendientes y al fortalecimiento de la Autonomía Regional, desde la Universidad.

Los proyectos y programas que abarcan las cuatro funciones sustantivas de la URACCAN: docencia, investigación, extensión social y comunitaria e internacionalización. Actualmente se expanden los horizontes espaciales, demográficos y temáticos de la Universidad, acordes a su modelo intercultural y comunitario. En el 2009, los proyectos y programas auspiciados por la cooperación internacional a la URACCAN totalizaron US\$4.19 millones aproximadamente. La visión, eficacia, costo efectividad y compromiso (mística) con que la Universidad desarrollo su quehacer la han convertido en un protagonista clave en el desarrollo integral en las Regiones Autónomas y el país, al mismo tiempo, ella es también una beneficiaria de los esfuerzos de fortalecimiento de las capacidades autonómicas de la comunidad internacional donante. El peso relativo del financiamiento total a la Universidad de estas fuentes en el 2009 es 8 por ciento fondos propios, 37 por ciento asignación Estatal y 55 por ciento cooperación internacional. A continuación se presenta un gráfico mostrando la tendencia del financiamiento Estatal y de Cooperación Internacional.

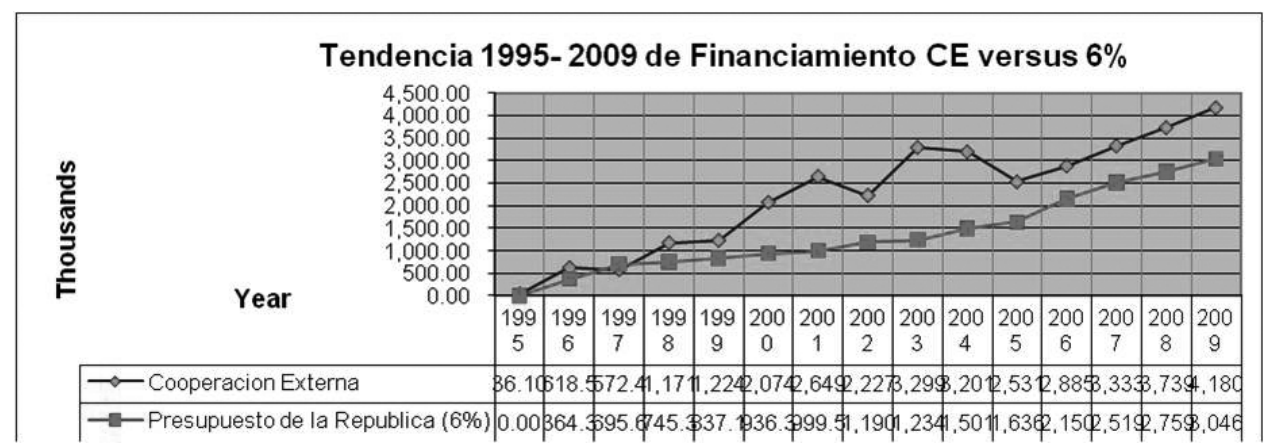

\section{Sus principales impactos}

La URACCAN es la principal institución autonómica, en referencia a sus aportes al avance y consolidación en la práctica del Estatuto de Autonomía. En todas sus funciones se tienen aportes sustanciales. Sus egresados y graduados no sólo son un suministro de recursos humanos valiosos a las Regiones Autónomas, sino que también representan una militancia para el futuro de la Autonomía Regional. Los estudiantes egresados y graduados de la URACCAN, durante su formación, interiorizan los valores, principios 


\section{CIENCIAS SOCIALES}

y compromisos por la autonomía y la interculturalidad (URACCAN, 2004b). Por otro lado, estos desarrollan competencias científico- técnicas acordes con las necesidades de la región, y de los empleadores dentro de esta (URACCAN, Informe de autoevaluación institucional, 2005). En una evaluación externa de pares, sobre el proyecto institucional de la URACCAN, se concluyó:

es interesante observar que tanto la comunidad universitaria como la comunidad en general se han apropiado de su filosofía, haciendo propio los postulados de la Visión y Misión, principalmente en los conceptos de Fortalecimiento del proceso de Autonomía y de Universidad Comunitaria" (BID, 2004). Este mismo estudio corroboró que "los programas y cursos son diseñados para fortalecer la identidad a la población a la que va dirigida y responden a la realidad y necesidad del territorio para que puedan ejercer sus derechos con mayor conocimiento. El currículo enfatiza el análisis y la investigación del proceso de Autonomía de la Costa Caribe de Nicaragua (Ibíd., pp. 15).

La URACCAN también se ha convertido en un espacio fundamental de diálogo y consenso autonómico. Entre algunos resultados importantes están el Sub-Sistema Educativo Autonómico Regional (SEAR), los Modelos de Salud Autonómico Regional de la RAAN y RAAS y la propuesta regional aprobada de la Ley de Demarcación y Titulación. La Universidad también aporta resultados de Investigaciones contextualizadas para la toma de decisión alrededor del proceso autonómico. En la actualidad se realiza la línea de base del SEAR en los municipios de Rosita, Bonanza y Laguna de Perlas. En el 2010 se ha realizado estudio sobre pautas de crianza de pueblos indígenas y afrodescendientes. Por otro lado, la extensión social y comunitaria impulsa el desarrollo con identidad, el buen vivir y ciudadanía intercultural. Como ejemplo, en la actualidad se impulsan procesos de revitalización cultural de los pueblos garífuna y sumo- mayangna. Se fomenta la forestería comunitaria en la RAAN y RAAS.

\section{La atención a estudiantes indígenas y afrodescendientes}

El surgimiento de la URACCAN tuvo tres motivaciones fundamentales. La primera motivación fue garantizar el derecho al ingreso a la Educación Superior a la población multiétnica del Caribe nicaragüense. Con la excepción de los intentos en las décadas de los 70, 80 e inicios de los 9o de establecer una extensión universitaria de la Universidad Nacional Autónoma de Nicaragua (UNAN- sede Managua) en el Caribe, el ingreso a la Educación Superior era una posibilidad de pocos hijos e hijas de familias caribeñas pudientes que podían sufragar sus gastos de estudio en el Pacífico (Managua y/o León). Al finalizar sus estudios, una mayoría terminaba quedándose en el Pacífico. La segunda motivación fue constituir un espacio propio de Educación Superior para crear dentro de las mismas Regiones Autónomas: las capacidades necesarias para impulsar la Autonomía Regional en todos sus ámbitos. A partir de este espacio se desarrollarían las competencias científico técnicas necesarias, se revitalizarían los saberes ancestrales, 
generaría conocimientos útiles y formaría un liderazgo ético, humanista, emprendedor y comprometido con la Autonomía Regional, la interculturalidad y la equidad de género. La tercera motivación, y la que le da el carácter intercultural y comunitario a la URACCAN, fue de garantizar el ingreso adecuado a la Educación Superior a los pueblos indígenas y afrodescendientes, conforme a sus necesidades de empoderamiento autonómico y superación de su severo rezago educativo, principalmente a nivel de Educación Terciaria. A continuación se abordan las diferentes estrategias utilizadas por la URACCAN, y su eficacia, para asegurar el ingreso, mantenimiento y graduación de los estudiantes de pueblos indígenas y afrodescendientes.

\section{Ingreso a la Educación Superior}

En la URACCAN, se han establecido tres estrategias de ingreso. La primera estrategia se ha asentado en tener una amplia presencia geográfica, priorizando las principales zonas etno- lingüísticas en las Regiones Autónomas. Así, se da el establecimiento de cuatro recintos y cuatro extensiones universitarias permanentes en la Costa Caribe nicaragüense. La decisión sobre el establecimiento de los recintos y extensiones se dio bajo el principio de la equidad, asegurando que todos los pueblos indígenas (miskito, mayangna y rama), afrodescendientes (kriol y garífuna) y comunidades mestizas (costeños y colonos) fueran atendidos según su valor estratégico para el avance de la Autonomía Regional. De esta manera, el Recinto Bilwi y su extensión Waspam están en el corazón del territorio miskito. El Recinto Bluefields se localiza en el centro histórico y cultural kriol, muy próximo a las únicas comunidades rama (en el municipio de Bluefields) y garífunas (en el municipio de Laguna de Perlas). Las extensiones en Bonanza y Rosita están en los municipios con mayor densidad de población sumomayangna (thawka y panamahka). Los Recintos Universitarios de Siuna y Nueva Guinea y la extensión de Waslala se establecieron en zonas de frontera agrícola, buscando como socializar a las comunidades mestizas en los valores y actitudes de la Autonomía Regional y la interculturalidad. Así mismo, la misión particular de estos recintos y extensión incluye el desarrollo de capacidades en esta población mestiza de frontera agrícola para transitar hacia sistemas de producción eco- sustentables, de perspectiva comunitaria.

La segunda estrategia de ingreso a la Educación Superior establecida por la URACCAN, es el desarrollo de una oferta académica diversificada, tanto en niveles de formación como en espacio geográfico de realización. En la oferta académica, se tiene institucionalizado el diplomado comunitario, la Escuela de Liderazgo y cursos de pregrado focalizados como mecanismos de democratización de ingreso de pueblos indígenas y afrodescendientes. Los diplomados comunitarios son un programa de estudio modular de entre 200 a 256 horas clases presenciales y prácticas que se realizan para desarrollar o mejorar las habilidades, capacidades y destrezas de líderes comunitarios y otros actores comunitarios claves para impulsar su propio desarrollo, 
desde sus prioridades y cosmovisión. Los diplomados se realizan en encuentros (de 3 a 9) en una comunidad céntrica del territorio cubierto y su duración total es de 12 a 18 meses, los facilitan los docentes del mismo pueblo, quienes aplican una metodología participativa bilingüe y el enfoque de aprender haciendo (teoría- práctica- teoría), especialmente mediante trabajos inter-encuentros de diagnóstico, elaboración y gestión de proyectos comunitarios. El currículo del diplomado es flexible, se complementa con materiales didácticos mediados pedagógicamente. Los principales requisitos de ingreso que exige la universidad es saber leer, escribir y contar con el aval de su comunidad, normalmente aprobado en una asamblea. La URACCAN ha desarrollado una oferta de cerca de 30 distintos diplomados, los que han tenido varias repeticiones. Estos son impulsados principalmente por los institutos y centros de la universidad. En una sistematización externa de los diplomados impulsados desde el IEPA en el período 1995- 2002, se logró estimar en 475 los líderes comunitarios miskitos y mayangnas graduados (NORDECO, 2002). En el cuadro siguiente se presenta una muestra de diplomados desarrollados desde los institutos y centros de la Universidad.

\begin{tabular}{ll}
\hline INSTITUTO & TíTULO DEL DIPLOMADO \\
\hline \multirow{2}{*}{ IEPA } & Gestión y desarrollo comunitario. \\
& Derechos indígenas y desarrollo comunitario. \\
& Mediación y resolución de conflictos. \\
\hline & Género y Desarrollo. \\
& Formación de Lideresas en Gestión y Desarrollo Comunitario con mención \\
& Autonómico. \\
& Sexualidad, poder y violencia. \\
& Tratamiento de la Violencia de Género. \\
& Formación de lideresas en gestión y desarrollo comunitario con mención \\
& Autonómica. \\
& Gestión empresarial intercultural. \\
\hline & Gestión y planificación ambiental. \\
& Diplomado Mesoamericano de Pueblos indígenas en Gestión Sustentable \\
& de la Biodiversidad. \\
& Gestión Comunitaria de Adaptación al Cambio Climático. \\
& Sistemas Agroforestales y Derechos Comunitarios. \\
& Fortalecimiento de pueblos indígenas y Manejo de Biodiversidad. \\
\hline IREMADES & Salud sexual y reproductiva con enfoque intercultural de género y VIH/ \\
& SIDA. \\
& Medicina Tradicional. \\
\hline \multirow{2}{*}{ IMTRADEC } & Actualización pedagógica en Educación Intercultural Bilingüe (EIB). \\
& Gestión Educativa del SEAR. \\
& Diplomado en Lengua, Arte y Cultura Garífuna. \\
\hline & Comunicación Social Comunitaria. \\
\hline
\end{tabular}


La Escuela de Liderazgo tiene un elevado valor estratégico dentro de la URACCAN y para los propios pueblos indígenas y afrodescendientes. La población indígena y afrodescendiente es mayoritariamente rural y padece de severos rezagos educativos, que se vuelven profundos en los niveles de Educación Secundaria y Terciaria. La Escuela de Liderazgo se ha establecido en los Recintos Universitarios de Siuna, Bilwi y Bluefields para funcionar como puente entre la Educación Primaria y la Educación Superior para jóvenes indígenas y afrodescendientes de comunidades rurales, las más remotas. La Escuela de Liderazgo tiene un currículo que cumple con los contenidos de secundaria y se amplia para cubrir las necesidades de formación en liderazgo. Tiene un régimen de internado. En el Recinto Siuna, que fue el primero en introducirla, se han dado 3 promociones. A la fecha, la universidad ha tenido un total de 204 estudiantes graduados de 7 generaciones de Escuelas de Liderazgo en los recintos Siuna, Bilwi y Bluefields. En el recinto de Bilwi, se tiene activo una Escuela de Liderazgo con 69 estudiantes. Estas 8 generaciones no han tenido estudiantes de los pueblos indígenas rama y garífuna graduados. A continuación se presenta un cuadro con las generaciones por recinto.

\begin{tabular}{lcccc}
\hline RECINTO & PROMOCIÓN & MISKITO & SUMO- MAYNAGNA & KRIOL \\
\hline \multirow{2}{*}{ SIUNA } & 2003 & - & 1 & - \\
\cline { 2 - 5 } & 2004 & - & 1 & - \\
\hline \multirow{3}{*}{ BILWI } & 2006 & 80 & 3 & 4 \\
\cline { 2 - 5 } & 2008 & 36 & 47 & 2 \\
\hline \multirow{2}{*}{ BLUEFIELDS } & 2011 & 66 & 3 & 2 \\
\cline { 2 - 5 } & 2008 & 10 & 9 & 3 \\
\hline TOTAL & 2009 & 2 & 4 & $\mathbf{1 1}$ \\
\hline
\end{tabular}

Fuente: Datos proporcionados por las oficinas de registro.

La URACCAN es la única universidad en Nicaragua que oferta carreras en Educación Intercultural Bilingüe (EIB), a nivel de diplomado, técnico superior, licenciatura y maestría, a partir del 2010. En el caso particular del técnico superior y/o la licenciatura en EIB, estas están dirigidas a la profesionalización del magisterio de pueblos indígenas y afrodescendientes pertenecientes al Programa de Educación Bilingüe Intercultural (PEBI). El Técnico Superior corresponde a los seis primeros semestres del currículo de la carrera, se tienen entre los requisitos de graduación prácticas docentes supervisadas, además de haber cumplido con el plan de estudio. La licenciatura corresponde a cuatro semestres adicionales y el requisito final de graduación la realización de un estudio monográfico. Este programa de estudio en EIB se han desarrollado en los recintos, extensiones y en la comunidad — caso de Laguna de Perlas y San Carlos río Coco- participando maestros y maestras en servicio del Ministerio de Educación, 
provenientes de comunidades rurales. Este programa, auspiciado por la cooperación internacional, incluye becas completas, que incluyen traslado, gastos de alojamiento, estipendio de alimentación y la provisión de materiales didácticos. Hasta el momento se tiene una graduación de estudiantes de los pueblos indígenas y afrodescendientes que representan un recurso valioso para el SEAR. Hasta el momento se tiene una graduación total de 254 estudiantes, que son maestros y maestras indígenas y afrodescendientes en servicio. Existe un grupo nuevo en Rosita que en el 2010 iniciaran sus estudios de licenciatura en EIB. En el siguiente cuadro se presenta un detalle de las graduaciones acumuladas hasta el 2009.

\begin{tabular}{|c|c|c|c|c|c|c|}
\hline RECINTO & 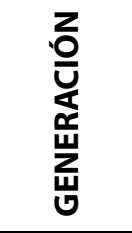 & $\begin{array}{l}\frac{\text { 을 }}{\Sigma} \\
\frac{\underline{u}}{\Sigma}\end{array}$ & 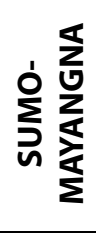 & $\sum_{\nwarrow}^{\nwarrow}$ & $\frac{\overrightarrow{0}}{\underline{x}}$ & $\frac{\overleftarrow{\zeta}}{\frac{\pi}{\sigma}}$ \\
\hline \multirow{5}{*}{ Bluefields } & 1998 & 1 & & & 2 & \\
\hline & 2001 & 1 & 1 & 1 & 5 & 1 \\
\hline & 2003 & 2 & 2 & 2 & 9 & 5 \\
\hline & 2006 & 4 & 6 & & 4 & 2 \\
\hline & 2009 & 4 & 4 & 1 & 11 & 4 \\
\hline \multirow{4}{*}{ Rosita } & 1998 & - & 26 & - & - & - \\
\hline & 2002 TS & - & 30 & - & - & - \\
\hline & 2002 & - & 25 & - & - & - \\
\hline & 2010 & - & & - & - & - \\
\hline Bonanza & 2002 TS & - & 28 & - & - & - \\
\hline \multirow{2}{*}{ Waspám } & 2002 TS & 34 & - & - & - & - \\
\hline & 2003 TS & 36 & - & - & - & - \\
\hline Bilwi & 2003 & 3 & - & - & - & - \\
\hline TOTAL & & 85 & 122 & 4 & 31 & 12 \\
\hline
\end{tabular}

Fuente: Datos de informes finales de proyectos.

La tercera estrategia es la oferta de becas internas a estudiantes de comunidades rurales alejadas para cursar estudios en las distintas carreras ofertadas por los recintos. Las becas internas incluyen alojamiento, alimentación y provisión de materiales didácticos y enseres personales. A los estudiantes se les brinda permanentemente tutorías académicas y atención psicológica. Los internados se financian con la partida presupuestaria asignada por el Estado nicaragüense. Las Oficina de Bienestar Estudiantil tiene a su cargo la coordinación de estos servicios. Los recintos de Siuna 
y Bluefields son los únicos con estas facilidades de ingreso. Del total de estudiantes becados internos, 171 estudiantes, el 40.35 por ciento (69 estudiantes) son estudiantes de pueblos indígenas y afrodescendientes. Los estudiantes indígenas miskito (28\%), sumo- mayangna (52\%) y kriol (15\%) son lo que tienen un mayor participación en los dos internados de la Universidad. En la siguiente tabla se detalla la participación de estudiantes indígena y afrodescendientes en los internados de la URACCAN al iniciar el primer semestre académico de 2010.

\begin{tabular}{lccccc}
\hline \multicolumn{1}{c}{ RECINTO } & MISKITO & $\begin{array}{c}\text { SUMO- } \\
\text { MAYANGNA }\end{array}$ & RAMA & KRIOL & GARÍFUNA \\
\hline Bluefields & 15 & 4 & 1 & 10 & 3 \\
\hline Siuna & 4 & 32 & & & \\
\hline TOTAL & $\mathbf{1 9}$ & $\mathbf{3 6}$ & $\mathbf{1}$ & $\mathbf{1 0}$ & $\mathbf{3}$ \\
\hline
\end{tabular}

Fuente: Datos proporcionados por las oficinas de registro.

Se debe mencionar que en el Recinto de Bluefields, 21 estudiantes graduados de la Escuela de Liderazgo han proseguido con estudios a nivel de licenciaturas e ingenierías. Los estudiantes están distribuidos 9 en la licenciatura en sociología, 7 en la ingeniería en agroforestería, 2 en la licenciatura en Administración de Empresas, 2 en la licenciatura en Psicología y 1 en la licenciatura en Informática Administrativa.

\section{Mantenimiento y graduación}

Para mejorar la retención estudiantil y graduación de los estudiantes de pueblos indígenas y afrodescendientes, la URACCAN ha impulsado importantes proyectos de fortalecimiento institucional auspiciados por organizaciones de cooperación internacional. En la autoevaluación institucional realizada en el período 2002- 2004, se encontraron importantes retos para el mantenimiento y la graduación de los estudiantes como poca lectura crítica, poco desarrollo investigativo, poca capacidad de redacción de informes técnicos, falta de orientación vocacional, docentes con débil formación pedagógica, limitaciones idiomáticas, económicas, en la base científico técnica en las áreas de español y matemáticas (URACCAN., 2005).

En base a esta información, se han desarrollado dos fases del Programa Pathaways for Higher Education de la Fundación Ford. En la primera fase desarrollada del 2005 al 2008 se abordó el establecimiento de servicios de apoyo académico a estudiantes en las áreas de español, inglés, matemáticas, metodologías de investigación, redacción técnica, informática y orientación vocacional; y capacitación a docentes en temas de técnicas de redacción, informática, lectura rápida, comunicación, enseñanza de lenguas y tecnologías de información. En esta fase se contribuyó a la graduación de 190 estudiantes indígenas y afrodescendientes y la capacitación de 118 docentes. En la segunda fase desarrollada de 2007 a 2008 fue abordado el apoyo a estudiantes 
indígenas y afrodescendientes en la realización de sus estudios monográficos, la capacitación de docentes en metodologías de investigación para que pudieran además ser mejores tutores. Los resultados principales de esta segunda fase fueron 20 estudiantes indígenas y afrodescendientes graduados y 30 docentes capacitados. Así mismo se elaboraron y publicaron los módulos de capacitación en metodologías de investigación para el uso de estudiantes y docentes.

Otros aliados importantes han sido el Fondo de Asistencia de los Estudiantes y Académicos Noruegos (SAIH) y HORIZONT30oo (ONG de Austria). En el período de 2006 hasta el 2012, SAIH ha provisto fondos para la realización de estudios monográficos de estudiantes indígenas y afrodescendientes y la capacitación de docentes, incluyendo el tema de investigación educativa. SAIH también está financiando la conclusión de una maestría en docencia universitaria para 32 docentes de los Recintos Universitarios de Bluefields y Nueva Guinea. En el caso particular de HORIZONT30oo, este ha financiado la realización de una maestría en docencia universitaria que graduó en el 2009 a 31 docentes del Recinto Siuna y sus extensiones de Rosita, Bonanza y Waslala principalmente. Estos proyectos han incidido favorablemente en el mantenimiento y graduación de los estudiantes.

Al finalizar el 2009, la retención estudiantil promedio en la URACCAN fue del 92 por ciento. En los cuatro recintos, la retención en el Recinto Bluefields fue del 97 por ciento, en el Recinto Nueva Guinea 95 por ciento, en el Recinto Bilwi 92 por ciento y en el Recinto Siuna 85 por ciento. La retención estudiantil por pueblo indígena y afrodescendiente varió entre los distintos recintos. La retención de estudiantes miskitos fue del 100 por ciento en el Recinto Bluefields, 96 por ciento en el Recinto Siuna y 90 por ciento en el Recinto Bilwi. La retención de estudiantes sumo- mayangnas fue del 100 por ciento en el Recinto Bluefields y 88 por ciento en el Recinto Siuna. La retención de estudiantes kriol fue de 98 por ciento en el Recinto Bluefields y 93 por ciento en el Recinto Bilwi. La retención de estudiantes rama fue del 100 por ciento en los técnicos superiores y 83 por ciento en licenciaturas e ingenierías en el Recinto Bluefields. La retención de estudiantes garífunas en el Recinto Bluefields ha sido del 100 por ciento tanto en técnicos superiores como en licenciaturas e ingenierías.

En los programas de formación y atención directa a los pueblos indígenas y afrodescendientes, los niveles de mantenimiento varían en los recintos. En las cinco generaciones de los técnicos superiores y/o licenciaturas en EIB ofertados en el Recinto Bluefields, los estudiantes miskitos, mayangnas, ramas, kriol y garífunas tuvieron niveles de egreso del 57.14 por ciento, 100 por ciento, 33.33 por ciento, 38.03 por ciento y 68.75 por ciento con respeto a su matrícula inicial. A nivel de graduación, los índices fueron del 38.10 por ciento, 100 por ciento, 33.33 por ciento, 50 por ciento y 28.17 por ciento para los estudiantes miskitos, sumo- mayangnas, rama, garífunas y kriol respectivamente con respecto a la matrícula inicial. En la dos generaciones de la Escuela de Liderazgo, el nivel de graduación de los estudiantes miskitos, mayangnas, 
rama, garífuna y kriol fue del 8 o por ciento, 130 por ciento, o por 10 y 26.31 por ciento. Un caso importante de notar fue la deserción total de los diez estudiantes ramas que iniciaron estudios en la Escuela de Liderazgo. Las principales razones identificadas de esta deserción fueron el poco involucramiento de las autoridades comunitarias en el seguimiento, expectativas sobre los ingresos a recibir en concepto de beca, discriminación de parte de otros estudiantes, formalidades del vestuario, añoranza de la comunidad, manejo del español y el régimen de internado al que no estaban acostumbrados (Koskinen, 2007).

En el Recinto Siuna, en los técnicos superiores y/o licenciaturas se tuvo un nivel de graduación del 85 por ciento aproximadamente de los estudiantes mayangnas. En las extensiones de Waspam y Bonanza el índice de graduación en los Técnicos Superiores en EIB ofertados fue del 93 por ciento de los estudiantes miskitos y 100 por ciento de los estudiantes sumo- mayangnas respectivamente. En el Recinto Bilwi el nivel de graduación de las dos generación de le Escuela de Liderazgo ha sido del 99 por ciento, tanto para estudiantes mayangnas como miskitos. Se debe notar que en estos programas los líderes comunitarios realizan un seguimiento in situ en forma permanente.

\section{Los principales retos de la URACCAN en la atención de estudiantes indígenas $y$ afrodescendientes}

En la atención a los estudiantes de pueblos indígenas y afrodescendientes, la URACCAN tiene un gran reto en términos de eficacia y eficiencia. Por un lado, existe la necesidad de incrementar significativamente el ingreso. Analizando los porcentajes de la matricula en la URACCAN por etnicidad de 2005 a 2010, en el cuadro siguiente, se puede observar que esta no varía con respecto al peso demográfico de los pueblos indígenas y afrodescendientes del total de la población de los municipios cubiertos por los recintos y extensiones de la Universidad. La matrícula de estudiantes mestizos de los recintos de Siuna y Nueva Guinea, incluidas sus extensiones, es un factor determinante de la "mestización" de la matrícula de la URACCAN. En este sentido, la matrícula 2010, los estudiantes mestizos de estos recintos representa el 69.23 por ciento de la matricula Mestiza total de la Universidad. La ampliación de las Escuelas de Liderazgo, el incremento de estudiantes becados internos y la ampliación de la oferta carreras directas a los pueblos indígenas y afrodescendientes son retos conexos fundamentales. Este reto es mayor para los casos del pueblo rama y garífuna, que tienen severas brechas de ingreso a los programas de formación de la URACCAN.

El peso demográfico de los pueblos indígenas y afrodescendientes en la matrícula de la URACCAN vis a vis su participación dentro de la matrícula de URACCAN 2005-2010 


\begin{tabular}{|c|c|c|c|c|c|c|}
\hline ETNIA & $\frac{\text { 을 }}{\frac{y}{n}}$ & 仓 & 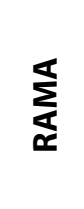 & $\frac{\overrightarrow{0}}{\underline{x}}$ & 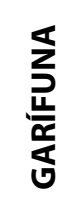 & $\stackrel{\text { 온 }}{\underline{n}}$ \\
\hline $\begin{array}{l}\text { PESO DEMOCRÁFICO EN LOS } \\
\text { MUNICIPIOS CUBIERTOS POR } \\
\text { URACCAN }\end{array}$ & 21.11 & 3.93 & 0.28 & 4.35 & 0.05 & 70.29 \\
\hline MATRÍCULA URACCAN 2010 & 14.62 & 5.38 & 0.35 & 4.53 & 0.56 & 74.57 \\
\hline MATRÍCULA URACCAN 2009 & 17.15 & 1.53 & 0.45 & 4.76 & 0.93 & 74.11 \\
\hline MATRICULA URACCAN 2008 & 7.27 & 1.55 & 0.20 & 2.27 & 0.39 & 29.24 \\
\hline MATRÍCULA URACCAN 2007 & 10.16 & 2.02 & 0.26 & 2.84 & 0.44 & 34.66 \\
\hline MATRÍCULA URACCAN 2006 & 23.18 & 3.12 & 0.91 & 6.28 & 0.44 & 51.55 \\
\hline MATRÍCULA URACCAN 2005 & 14.09 & 2.87 & 0.00 & 1.70 & 0.05 & 40.23 \\
\hline
\end{tabular}

Fuente: Datos proporcionados por las oficinas de registro.

En el nivel de graduación, derivado de las brechas de ingreso, la URACCAN tiene de igual manera el reto de la inclusión de los pueblos indígenas y afrodescendientes. Según el siguiente cuadro, el 62.24 por ciento de los estudiantes graduados en el período 2008-2010 son mestizos y el 37.76 por ciento estudiantes indígenas y afrodescendiente. Del total de estudiantes graduados, los mayores porcentajes de graduación en pueblos indígenas y afrodescendientes fueron para estudiantes miskitos con el 20 por ciento, sumo- mayangnas con el 9 por ciento y kriol con el 5 por ciento. En este período, sólo se graduaron 3 estudiantes ramas y 8 garífunas.

\begin{tabular}{|c|c|c|c|c|c|c|c|c|}
\hline RECINTO & AÑO & $\begin{array}{l}\text { 을 } \\
\frac{\text { n }}{\Sigma}\end{array}$ & 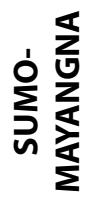 & $\sum_{\nwarrow}^{\mathbb{\Phi}}$ & $\frac{\overrightarrow{\underline{0}}}{\underline{x}}$ & $\frac{\nwarrow}{\vdots}$ & 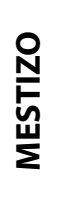 & TOTAL \\
\hline \multirow{4}{*}{ Bilwi } & 2010 & 18 & & & 2 & & 3 & 23 \\
\hline & 2009 & 27 & 0 & 0 & 0 & 1 & 19 & 63 \\
\hline & 2008 & 152 & 44 & 0 & 18 & 0 & 58 & 287 \\
\hline & 2010 & 0 & 0 & 0 & 6 & 0 & 12 & 18 \\
\hline \multirow{2}{*}{ Bluefields } & 2009 & 14 & 12 & 3 & 29 & 7 & 76 & 141 \\
\hline & 2008 & 2 & 1 & 0 & 4 & 0 & 11 & 18 \\
\hline
\end{tabular}




\begin{tabular}{|c|c|c|c|c|c|c|c|c|}
\hline RECINTO & AÑO & $\begin{array}{l}\text { 을 } \\
\frac{\mathbf{u}}{\mathrm{n}} \\
\sum\end{array}$ & 方 & 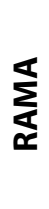 & $\frac{\overrightarrow{0}}{\underline{x}}$ & $\frac{\nwarrow}{Z}$ & 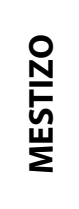 & TOTAL \\
\hline \multirow{4}{*}{ Siuna } & 2010 & & 1 & & & & 18 & 19 \\
\hline & 2009 & 2 & 1 & 0 & 0 & 0 & 96 & 99 \\
\hline & 2008 & 9 & 37 & 0 & 0 & 0 & 250 & 296 \\
\hline & 2010 & 0 & 0 & 0 & 0 & 0 & 0 & 0 \\
\hline \multirow{2}{*}{$\begin{array}{l}\text { Nueva } \\
\text { Guinea }\end{array}$} & 2009 & 0 & 0 & 0 & 0 & 0 & 58 & 58 \\
\hline & 2008 & 0 & 0 & 0 & 0 & 0 & 93 & 93 \\
\hline TOTAL & & 224 & 96 & 3 & 59 & 8 & 694 & 1,115 \\
\hline
\end{tabular}

Fuente: Elaboración propia conforme a datos proporcionados por la Dirección General de Registro.

En el logro de graduación, el recurso docente juega un papel importante tanto por el acompañamiento académico a los estudiantes como en el sociocultural. La URACCAN ha sido consciente de que su planta docente debe ser intercultural, pero principalmente hay que asegurar y abrir las brechas de ingreso a estos puestos por parte de los pueblos indígenas y afrodescendientes. En el 2009, el 75.7 por ciento de los docentes eran mestizos, el 11.7 por ciento miskito, el 9.3 por ciento kriol, el 2.3 por ciento sumo- mayangna, el 0.7 por ciento rama y el 0.3 por ciento garífuna. Muchos de los docentes indígenas y afrodescendientes de la URACCAN han egresadp de sus programas de formación, tanto en el nivel de pregrado como postgrado. En este campo existen brechas que reducir. El cuadro siguiente detalla la planta docente por cada Recinto Universitario.

\begin{tabular}{|c|c|c|c|c|c|c|c|}
\hline RECINTO & $\begin{array}{l}\text { 을 } \\
\frac{\mathbf{u}}{\Sigma} \\
\sum\end{array}$ & 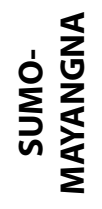 & $\sum_{\nwarrow}^{\frac{\pi}{\alpha}}$ & $\frac{\overrightarrow{0}}{\frac{\underline{x}}{x}}$ & $\frac{\nwarrow}{z}$ & 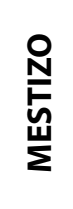 & TOTAL \\
\hline Bilwi & 33 & 2 & 0 & 11 & - & 43 & 89 \\
\hline Bluefields & 2 & 0 & 2 & 16 & 1 & 62 & 83 \\
\hline Siuna & 0 & 5 & 0 & 0 & - & 65 & 70 \\
\hline $\begin{array}{l}\text { Nueva } \\
\text { Guinea }\end{array}$ & 0 & 0 & $\mathrm{O}$ & 1 & - & 57 & 58 \\
\hline TOTAL & 35 & 7 & 2 & 28 & 1 & 227 & 300 \\
\hline
\end{tabular}

Fuente: Datos proporcionados por la Dirección General de Registro. 


\section{CIENCIAS SOCIALES}

\section{Conclusiones}

Desde su corta vida, la URACCAN constituye un actor clave en el fortalecimiento de la Autonomía en sus funciones de docencia, investigación y extensión social y comunitaria. Su proceso de formación trasmite los valores de la autonomía, la equidad de género y la interculturalidad, principalmente. Sus investigaciones contribuyen a crear una base de conocimientos e información que nutre el proceso autonómico. Sus proyectos y programas de extensión social y comunitaria revitalizan la cultura, fortalecen las capacidades productivas y sociales. Los avances de la labor de la URACCAN es el acompañamiento en el proceso de construcción de la Autonomía Regional. El posicionamiento de la Autonomía en el sector mestizo ha sido fundamental. A 15 años de una práctica universitaria, el mayor reto que tiene la URACCAN es la construcción de interculturalidad hacia adentro, especialmente la atención a estudiantes indígenas y afrodescendientes y disponer de una mayor participación de docentes indígenas y afrodescendientes en su personal. La decisión original de establecer los recintos y extensiones ha sido eficaz para democratizar en general el ingreso a Educación Superior relevante en las Regiones Autónomas. El costo pagado ha sido en la capacidad de democratizar ingreso, especialmente a pueblos como el rama y garífuna.

En la nueva etapa que inicia la URACCAN en el 2010, que incluye un proceso de reflexión sobre eficacia, y con ello el resultante plan de mejora o reingeniería. La interculturalidad es un eje que requiere un amplio proceso de reflexión y consenso, en correspondencia con el modelo de universidad intercultural comunitario en construcción. Este proceso debe reconocer que los aportes hechos son significativos en el contexto del severo rezago educativo de los pueblos indígenas y afrodescendientes, especialmente el rama y garífuna. El rezago educativo estructural es entonces una variable importante que se debe considerar en la redefinición de las estrategias de ingreso, mantenimiento y graduación de estudiantes indígenas y afrodescendientes en la URACCAN. La optimización de los recursos disponibles deberá ser un factor importante para poder cumplir con los objetivos de interculturalidad hacia adentro. $\mathrm{Y}$ en su momento, las autoridades universitarias deben considerar la asignación presupuestaria a los recintos considerando estas variables. En la URACCAN siempre se ha mantenido como lema que la construcción de universidad propia es uno de los mayores retos de la Autonomía. Precisamente, este trabajo muestra precisamente que existen importantes brechas que superar. 


\section{Lista de referencias}

BID, M. (2004). Infome de evaluación externa a URACCAN. Comisión de pares evaluadores externos. Managua: MHCP- BID, Ministerio de Hacienda y Crédito PúblicoBanco Interamericano de Desarrollo.

Delgadillo, M. (2007). Desigualdades sociodemográficas en Nicaragua: tendencias, relevancia y politicas pertinentes. Santiago de Chile: CEPAL y UNFPA.

FOREIBCA, P. f. (2000). Estudio de línea base del PEBI. Bluefields: URACCAN, Universidad de las Regiones Autónomas de la Costa Caribe Nicaragüense.

Frühling, P., González, M., \& Buvollen, H. P. (2007). Etnicidad y nación. El desarrollo de la Costa Atlántica de Nicaragua (1987- 2007). Guatemala: F\&G Editores.

INEC, I. N. (2006). VIII Censo de población y IV de vivienda, 2005. Cifras oficiales. Managua: Gobierno de Nicaragua.

INIDE, I. N. (2007). Perfil y características de los pobres en Nicaragua 2005. Encuesta nacional de hogares sobre medición del nivel de vida 2005. . Managua: Gobierno de Nicaragua.

Jamieson, m. (1999). Poverty among the indigenous peoples of Nicaragua. Washington, DC, United States of America: IADB, Inter- American Development bank.

Koskinen, A. (2007). Formando líderes y liderezas- fortaleciendo la Autonomía. Sistematización de la experiencia de la Escuela de Liderazgo Comunitario 20052007. Bluefields: URACCAN.

López Segrega, F., Brock, C., \& Dias Sobrinho, J. (2009). Higher education in Latin America and the Caribbean 2008. Caracas: IESALC- UNESCO, Instituto Internacional de la UNESCO para la Educación Superior en América Latina y el Caribe.

MINED, M. d. (2008). Censo escolar 2007. Informe de los departamentos y Regiones Autónomas. Managua: Gobierno de Nicaragua.

Nicaragua, G. d. (2008). Readiness project idea note. Managua: MARENA- MAGFORINAFOR, Ministerio de Recursos Naturales y Medio Ambiente- Ministerio Agropecuario y Forestal- Instituto Nacional Forestal.

NORDECO. (2002). Sistematización del proceso de implementación de los diplomados de IEPA entre 1995- 2002 y algunas proyecciones hacia el futuro. Informe de asistencia técnica dentro del Programa de Fortalecimiento de Capacidades Locales (PROFCAL). 
Managua: NORDECO- BID, Agencia Nórdica de Desarrollo y Ecología- Banco Interamericano de Desarrollo.

PNUD, P. d. (2005). Informe de Desarrollo Humano 2005. Las Regiones de la Costa Caribe ¿Nicaragua asume su diversidad? Managua: PNUD.

Del Cid Lucero, Vìctor Manuel (2005). Diez años de cooperación de SAIH-Noruega. Para el mejoramiento de la calidad docente y académica en la Costa Caribe de Nicaragua. Informe de evaluación de impacto. Managua: URACCAN, Universidad de las Regiones Autónomas de la Costa Caribe Nicaragüense.

URACCAN. (2004). El proceso social y político de la construcción de la autonomía en las Regiones Autónomas de la Costa Caribe nicaragüense. Capítulo II del informe de desarrollo humano de la Costa Caribe ¿Nicaragua asume su diversidad? Regiones Autónomas. Bluefields: URACCAN, Universidad de las Regiones Autónomas de la Costa Caribe Nicaragüense.

URACCAN (2005). Informe de autoevaluación institucional. Bilwi: URACCAN.

URACCAN (2003). Informe de gestión 1994- 2002. Hacia la autonomía por la universidad. Managua: URACCAN, Universidad de las Regiones Autónomas de la Costa Caribe Nicaragüense.

URACCAN (2006). Informe de gestión 2003- 2006. Bilwi: URACCAN, Universidad de las Regiones Autónomas de la Costa Caribe Nicaragüense.

URACCAN (2007). Informe de gestión 2007. Bilwi: URACCAN, Universidad de las Regiones Autónomas de la Costa Caribe Nicaragüense.

URACCAN (2008). Informe de gestión institucional 2008. Bilwi: URACCAN, Universidad de las Regiones Autónomas de la Costa Caribe Nicaragüense.

URACCAN (2009). Informe de gestión institucional 2009. Bilwi: URACCAN, Universidad de las Regiones Autónomas de la Costa Caribe Nicaragüense.

URACCAN (2005). Informe de proceso de auto evaluación institucional. Bilwi: URACCAN, Universidad de las Regiones Autónomas de la Costa Caribe Nicaragüense.

URACCAN (2007). Reglamento de postgrados y educación continua. Managua: URACCAN, Universidad de las Regiones Autónomas de la Costa Caribe Nicaragüense.

URACCAN (2004). URACCAN: A diez años de funcionamiento, una visión interna sobre la práctica de la autonomía e interculturalidad. Investigación realizada dentro del 
marco del Proyecto Educación Ciudadana Intercultural para pueblos indígenas de América Latina en Situacio. Bilwi: URACCAN, Universidad de las Regiones Autónomas de la Costa Caribe Nicaragüense.

Williamson Cuthbert, D. N., \& Fonseca Duarte, G. (2007). Compendio estadístico de las Regiones Autónomas de la Costa Caribe de Nicaragua. Managua: CIDCA- UCA, Centro de Investigaciones y Documentación de la Costa Atlántica de NicaraguaUniversidad Centroamericana.

Zapata, Y. (2007). Histografía, sociedad y autonomía. Desde Tuluwalpa hasta las Regiones Autónomas de la Costa Caribe nicaragüense: un pasado y un presente diferente. Tomo 1. Managua: URACCAN. 